Check for updates

Cite this: RSC Adv., 2020, 10, 1828

DOI: $10.1039 / c 9 r a 90099 c$

rsc.li/rsc-advances

\section{Correction: Visible-light photocatalytic performance, recovery and degradation mechanism of ternary magnetic $\mathrm{Fe}_{3} \mathrm{O}_{4} / \mathrm{BiOBr} / \mathrm{BiOl}$ composite}

\author{
Jianhui Li, Fan Yang, Quan Zhou, Lijie Wu, Wenying Li, Ruipeng Ren* \\ and Yongkang LV iD*
}

Correction for 'Visible-light photocatalytic performance, recovery and degradation mechanism of ternary magnetic $\mathrm{Fe}_{3} \mathrm{O}_{4} / \mathrm{BiOBr} / \mathrm{BiOl}$ composite' by Jianhui Li et al., RSC Adv., 2019, 9, 23545-23553.

The authors regret that incorrect insets were shown in Fig. 9b in the original manuscript. An SEM image of the composite before the reaction was shown in the top inset, whereas an image after the reaction should have been shown. The correct figure is shown below.
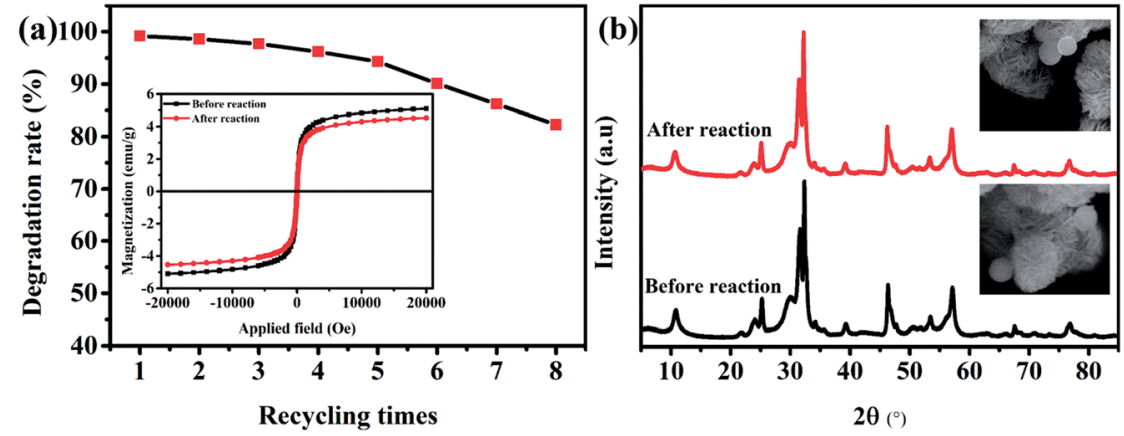

Fig. 9 (a) Recycling utilization experiments and magnetism of $\mathrm{Fe}_{3} \mathrm{O}_{4} / \mathrm{BiOBr} / \mathrm{BiOI}(0.4: 3: 1)$ composite before and after recycling (inset); (b) XRD patterns and $\mathrm{SEM}$ images (inset) of $\mathrm{Fe}_{3} \mathrm{O}_{4} / \mathrm{BiOBr} / \mathrm{BiOI}(0.4: 3: 1)$ composite before and after recycling.

In addition, on page 23548 in the section on Morphology and composition characterization, the molar ratio of $\mathrm{Bi}: \mathrm{O}: \mathrm{Br}: \mathrm{I}: \mathrm{Fe}$ in the EDS analysis of the composite was incorrectly shown as $19: 33: 15: 48: 57$. Therefore, the sentence beginning "What is more, the quantitative result presents the atomic..." should be corrected as shown below:

What is more, the quantitative result presents the atomic of $\mathrm{Bi}: \mathrm{O}: \mathrm{Br}: \mathrm{I}: \mathrm{Fe}$ in the ternary magnetic $\mathrm{Fe}_{3} \mathrm{O}_{4} / \mathrm{BiOBr} / \mathrm{BiOI}$ $(0.4: 3: 1)$ composite is $48: 57: 33: 15: 19$, which is in line with theoretical chemometrics ratio of $20: 28: 15: 5: 6$ for $\mathrm{Bi}: \mathrm{O}: \mathrm{Br}: \mathrm{I}: \mathrm{Fe}$ in $\mathrm{Fe}_{3} \mathrm{O}_{4} / \mathrm{BiOBr} / \mathrm{BiOI}(0.4: 3: 1)$ in view of instrumental error, implying that the mole ratio of $\mathrm{Fe}_{3} \mathrm{O}_{4}, \mathrm{BiOBr}$ and BiOI in the ternary magnetic $\mathrm{Fe}_{3} \mathrm{O}_{4} / \mathrm{BiOBr} / \mathrm{BiOI}(0.4: 3: 1)$ composite is $0.4: 3: 1$.

The Royal Society of Chemistry apologises for these errors and any consequent inconvenience to authors and readers. 